\title{
Mass transport techniques as a tool for a better understanding of the structure of L-Dopa in aqueous solutions
}

\author{
Marisa C.F. Barros ${ }^{\mathrm{a}, \mathrm{c}}$, Ana C.F. Ribeiro ${ }^{\mathrm{a}, *}$, Artur J.M. Valente ${ }^{\mathrm{a}}$, Victor M.M. Lobo $^{\mathrm{a}}$, Ana M.T.D.P.V. Cabral $^{\mathrm{b}}$, \\ Francisco J.B. Veigab ${ }^{\mathrm{b}}$, Carmen Teijeiro $^{\mathrm{c}}$, Miguel A. Esteso ${ }^{\mathrm{c}, * *}$ \\ a Department of Chemistry, University of Coimbra, 3004-535 Coimbra, Portugal \\ ${ }^{\mathrm{b}}$ Faculty of Pharmacy, University of Coimbra, 3000-295 Coimbra, Portugal

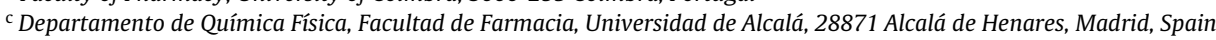

\section{A R T I C L E I N F O}

\section{Article history:}

Received 27 December 2012

Received in revised form 21 February 2013

Accepted 22 February 2013

Available online 4 March 2013

\section{Keywords:}

Parkinson disease

Levodopa

Diffusion coefficients

Transport properties

Solutions

\begin{abstract}
A B S T R A C T
Mutual diffusion coefficients, $D$, densities, $\rho$, and viscosities, $\eta$, are reported for aqueous solutions of L-3,4-dihydroxyphenylalanine ( $\mathrm{L}-\mathrm{Dopa}$ ) at $298.15 \mathrm{~K}$ and $310.15 \mathrm{~K}$ at concentrations from $(0.00025$ to $0.0075) \mathrm{mol} \mathrm{dm}^{-3}$. The aim of this study is to contribute to a better understanding of the structure of these systems and the thermodynamic behaviour of L-Dopa in solution. Thus, from these experimental data it was possible to estimate some parameters, such as the hydrodynamic radius, $R_{\mathrm{h}}$, apparent molar volumes, $\phi_{\mathrm{V}}$, and diffusion coefficients at infinitesimal concentration, $D^{0}$, essential for a better understanding of disperse systems. From the measured diffusion coefficients, activity coefficients, $\gamma$, for aqueous L-Dopa solutions were also estimated by using Nernst-Hartley equation. The effect of the viscosity on the estimated hydrodynamic radius was also studied.
\end{abstract}

(C) 2013 Elsevier B.V. All rights reserved.

\section{Introduction}

In the early 1960's, L-3,4-dihydroxyphenylalanine (levodopa, also called L-Dopa), a precursor of the neurotransmitters dopamine, was one of the most surprising neurological drugs as a result of its ability to induce a direct improvement in patients with Parkinson's disease, due to its conversion into dopamine in both the central nervous system and the peripheral nervous system (Carlsson, 2002).

However, the properties of the aqueous systems containing this drug are poorly known. For example, being usually orally administered and rapidly absorbed, the extension of the absorption and its clinical response depend on multiple factors, such as the stomach and intestine $\mathrm{pH}$, and the concentrations of the inorganic salts present there. In fact, there are common adverse effects in the use of L-Dopa (Cotzias et al., 1967, 1969), from what some authors have suggest associating it with inorganic matrices that might result in delayed or controlled release, obtaining this way the better regulation of L-Dopa uptake and avoiding the side effects of this drug.

\footnotetext{
* Corresponding author. Tel.: +351239 854460; fax: +351239827703.

** Corresponding author. Tel.: +34 918854861; fax: +34 918854763.

E-mail addresses: marisa.barros@gmail.com (M.C.F. Barros), anacfrib@ci.uc.pt (A.C.F. Ribeiro), avalente@ci.uc.pt (A.J.M. Valente), vlobo@ci.uc.pt (V.M.M. Lobo), acabral@ff.uc.pt (A.M.T.D.P.V. Cabral), fveiga@ci.uc.pt (F.J.B. Veiga), carmen.teijeiro@uah.es (C. Teijeiro), miguel.esteso@uah.es (M.A. Esteso).
}

This has provided our impetus for the present study. Having in mind that we are particularly interested in data concerning diffusion and viscosity, and as far as the authors know, there are no data available, the present work intends to fill this gap.

As a consequence, we have also estimated some structural, thermodynamic and transport parameters, such as activity coefficients, apparent molar volumes, limiting diffusion coefficients and hydrodynamic radius of L-Dopa aqueous solutions. These data will contribute for the design of better matrices and appropriate conditions for the release and uptake of L-Dopa.

\section{Experimental}

\subsection{Reagents and solutions}

The 3-(3,4-dihydroxyphenyl)-L-alanina (L-Dopa, Fluka, purum $\geq 99 \% ; M=197.19 \mathrm{~g} \mathrm{~mol}^{-1}$ ) was used as received (Table 1 ).

All the solutions were freshly prepared before each experiment. For diffusion studies, they were prepared by volume (concentration uncertainty less than $0.1 \%$ ) and de-aerated during $30 \mathrm{~min}$, approximately, before use. For the density and viscosity measurements, solutions were prepared by direct weighing both the solute and distilled water in a Mettler AE 240 balance with a precision of $\pm 0.0001 \mathrm{~g}$ (the uncertainty concerning composition was less than $\pm 0.07 \%$ ). 
Table 1

Sample description.

\begin{tabular}{lll}
\hline Chemical name & Source & Mass fraction purity \\
\hline L-Dopa & Fluka & $\geq 99 \%$ \\
\hline
\end{tabular}

\subsection{Diffusion measurements}

The theory of the Taylor dispersion technique is well described in the literature (Taylor, 1953; Ribeiro et al., 2010). Therefore, only some relevant points on the experimental determination of binary diffusion coefficients, $D$, will be indicated.

The method is based on the dispersion of small amounts of solution into a laminar carrier stream of solvent or solution of different composition, flowing through a long capillary tube $\left((3.2799 \pm 0.0001) 10^{4} \mathrm{~mm}\right.$ in length and a radius of $0.5570 \pm 0.0003 \mathrm{~mm}$ ) (Ribeiro et al., 2005, 2011a, 2011b; Valente et al., 2011).

A 6-port Teflon injection valve (Rheodyne, model 5020) was used to introduce $0.063 \mathrm{~mL}$ of solution into the laminar carrier stream of slightly different composition. A flow rate of $0.17 \mathrm{~mL} \mathrm{~min}^{-1}$ was maintained by a metering pump (Gilson model Minipuls 3) to give retention times of about $1.1 \times 10^{4} \mathrm{~s}$. The dispersion tube and the injection valve were kept at (298.15 and 310.15) $\mathrm{K} \pm(0.01 \mathrm{~K})$ in an air thermostat.

Dispersion of the injected samples was monitored using a differential refractometer (Waters model 2410) at the outlet of the dispersion tube (Fig. 1). Detector voltages, $V(t)$, were measured at accurately $5 \mathrm{~s}$ intervals with a digital voltmeter (Agilent $34401 \mathrm{~A}$ ) with an IEEE interface. Binary diffusion coefficients were evaluated by fitting the dispersion equation

$V(t)=V_{0}+V_{1} t+V_{\max }\left(t_{\mathrm{R}} / t\right)^{1 / 2} \exp \left[-12 D\left(t-t_{\mathrm{R}}\right)^{2} / r^{2} t\right]$

to the detector voltages. The additional fitting parameters were the mean sample retention time $t_{R}$, peak height $V_{\text {max }}$, baseline voltage $V_{0}$, and baseline slope $V_{1}$.

Binary mutual diffusion coefficients $(D)$ are calculated from the broadened distribution of the dispersed sample measured at the tube outlet (e.g. Callendar and Leaist, 2006).

In these experiments, small volumes, $\Delta V$, of the solution, of composition $\overline{c_{1}}+\overline{\Delta c_{1}}$ and $\overline{c_{2}}+\overline{\Delta c_{2}}$ are injected into carrier solutions of composition $\bar{c}_{1}$ and $\bar{c}_{2}$ at time $t=0$.

\subsection{Density measurements}

The density of these solutions was determined with an Anton Paar DMA5000 M densimeter (precision of $1 \times 10^{-6} \mathrm{~g} \mathrm{~cm}^{-3}$ and accuracy of $5 \times 10^{-6} \mathrm{~g} \mathrm{~cm}^{-3}$ in the ranges of $0-90^{\circ} \mathrm{C}$ of temperature and $0-10$ bars of pressure). This densimeter is provided with a Peltier system which allows keeping the temperature of the

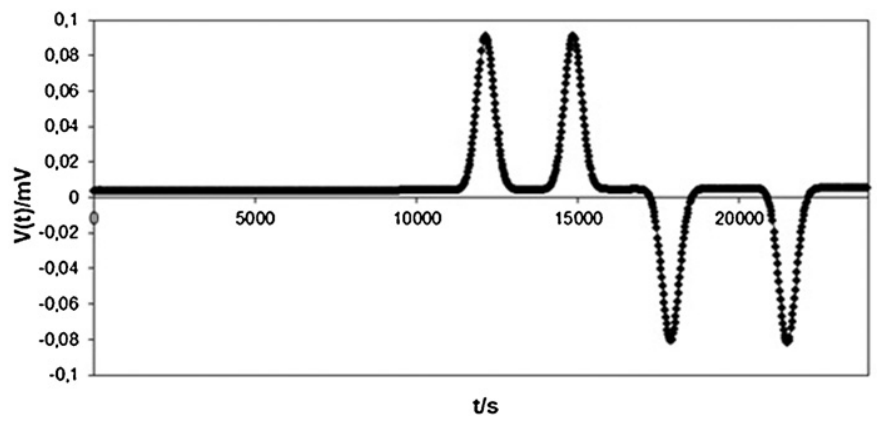

Fig. 1. Dispersion profile of a L-Dopa standard Taylor experience.
Table 2

Experimental mutual diffusion coefficients, $D_{\exp }$ for aqueous L-Dopa solutions at various concentrations, $c$, and temperatures.

\begin{tabular}{lll}
\hline$c\left(\mathrm{~mol} \mathrm{dm}^{-3}\right)$ & $\left(D \pm S_{D}\right)\left(10^{-9} \mathrm{~m}^{2} \mathrm{~s}^{-1}\right)^{\mathrm{a}}$ \\
\cline { 2 - 3 } & $T(\mathrm{~K})=298.15$ & $T(\mathrm{~K})=310.15$ \\
\hline 0.000250 & $0.635 \pm 0.004$ & $0.849 \pm 0.055$ \\
0.000500 & $0.631 \pm 0.005$ & $0.845 \pm 0.004$ \\
0.001001 & $0.627 \pm 0.012$ & $0.839 \pm 0.011$ \\
0.001751 & $0.622 \pm 0.015$ & $0.837 \pm 0.025$ \\
0.002501 & $0.612 \pm 0.008$ & $0.835 \pm 0.006$ \\
0.003749 & $0.600 \pm 0.026$ & $0.829 \pm 0.030$ \\
0.005001 & $0.628 \pm 0.010$ & $0.852 \pm 0.007$ \\
0.006000 & $0.642 \pm 0.018$ & $0.856 \pm 0.010$ \\
0.007001 & $0.661 \pm 0.012$ & $0.888 \pm 0.028$ \\
\hline
\end{tabular}

a $D$ and $S_{D}$ are the mean diffusion coefficient for 4 experiments and the respective standard deviations of that mean.; $\mathrm{u}(c)=5 \times 10^{-6} \mathrm{~mol} \mathrm{dm}^{-3}$. $\mathrm{u}(D)=0.02 \times 10^{-9} \mathrm{~m}^{2} \mathrm{~s}^{-1} ; \mathrm{u}(T)=0.01 \mathrm{~K}$.

samples constant during the measurement within $\pm 0.005^{\circ}$. They were carried out at $298.15 \mathrm{~K}$ and $310.15 \mathrm{~K}$.

The density value for each solution studied was the mean one of at least four sets of measurements. These values were reproducible within $\pm 0.001 \%$ of uncertainty.

\subsection{Viscosity measurements}

Viscosity measurements were performed with an Ostwald type viscometer (capillary diameter $=0.30 \mathrm{~mm}$ ), calibrated from water, immersed in a water-thermostat bath which temperature was controlled within $\pm 0.02 \mathrm{~K}$ by using a digital thermometer. The arithmetic mean value of four sets of flow times for each solution was taken to calculate such viscosity values. The efflux time was carried out with a stopwatch with a resolution of $0.2 \mathrm{~s}$. These values were reproducible within $\pm 0.1 \%$ of uncertainty ( $\pm 0.001 \mathrm{mPa}$ ).

Since the efflux times were always greater than 350-400 s, the kinetic energy correction (Hagenbach correction) was considered to be not necessary and, therefore, viscosity values (in mPa s) were evaluated from the equation:

$\eta=K \rho t$

where $K$ (equal to $0.0025314 \mathrm{~mm}^{2} \mathrm{~s}^{-2}$ and $0.0025294 \mathrm{~mm}^{2} \mathrm{~s}^{-2}$ at 25 and $37^{\circ} \mathrm{C}$, respectively) is the viscometer constants, $\rho$ the density $\left(\mathrm{g} \mathrm{cm}^{-3}\right)$ and $t$ the flow time $(\mathrm{s})$.

The measurements were carried out in each solution and in pure water. By applying Eq. (2) to them and combining adequately, the expression:

$\frac{\eta}{\eta_{0}}=\frac{\rho t}{\rho_{0} t_{0}}$

is obtained, where $\eta_{0}, \rho_{0}$ and $t_{0}$ are referred to pure water. From this Eq. (3) the viscosity of the corresponding solution, $\eta$, was calculated. The values used for the viscosity of water were $0.8902 \mathrm{mPa} \mathrm{s}$ and $0.6925 \mathrm{mPa} s$ at 25 and $37^{\circ} \mathrm{C}$, respectively (Kestin et al., 1978) and those of the density, $0.997048 \mathrm{~g} \mathrm{~cm}^{-3}$ and $0.993333 \mathrm{~g} \mathrm{~cm}^{-3}$ at 25 and $37^{\circ} \mathrm{C}$, respectively (Lide, 2007-2008).

\section{Results and discussion}

Diffusion coefficient values for binary systems, $D$, together with the standard deviations of the mean at $T=298.15 \mathrm{~K}$ and $T=310.15 \mathrm{~K}$ are summarized in Table 2. These results are, in general, the average ones from 4 independent experiments, with an uncertainty of (1-2)\% (Ribeiro et al., 2012).

The concentration dependence of the measured diffusion coefficients is accurately represented by the linear equation:

$D=D_{0}(1+a c)$ 
Table 3

Values of the parameters $D^{0}$ and $a$ for the dependence of $D$ with concentration in aqueous solutions of L-Dopa at $298.15 \mathrm{~K}$ and $310.15 \mathrm{~K}^{\mathrm{a}}$

\begin{tabular}{llrl}
\hline$T(\mathrm{~K})$ & $D^{0}$ & \multicolumn{1}{l}{$a$} & $r^{2}$ \\
\hline 298.15 & $0.637 \pm 0.001$ & $-9.8 \pm 0.4$ & 0.991 \\
310.15 & $0.847 \pm 0.002$ & $-13.7 \pm 0.8$ & 0.914 \\
\hline
\end{tabular}

a These fittings were performed for $c \leq 0.00375 \mathrm{~mol} \mathrm{dm}^{-3}$ (see Table 2).

where $D^{0}$ is the diffusion coefficient at infinitesimal concentration (in $\mathrm{m}^{2} \mathrm{~s}^{-1}$ ) and $a$ is a constant (in $\mathrm{dm}^{3} \mathrm{~mol}^{-1}$ ); both these parameters were computed by fitting the Eq. (4) to experimental data by using a least-squares procedure (Table 3 ).

From the binary diffusion coefficients (Table 2), we may estimate the activity coefficients for aqueous L-Dopa solutions, using the Nernst-Hartley equation (Eq. (5)) applicable to non-electrolytes (Tyrrell and Harris, 1984; Ribeiro et al., 2011c)

$D=D_{0}\left(1+\frac{d \ln \gamma}{d \ln c}\right)_{T, P}$

where $\gamma$ is the thermodynamic activity coefficient of that drug. Its application can be justified if we consider that in those solutions (for which the acid $\mathrm{pH}$ conditions promote the dissociation of the carboxylic group and the protonation of the amino one) the levodopa molecules predominantly exist as a zwitterion (Chen et al., 2004)

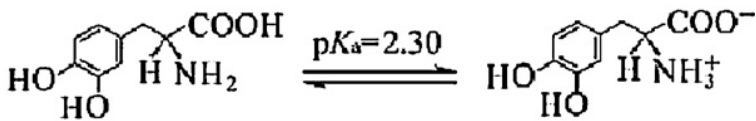

In addition, for dilute solutions $\left(c \leq 0.00375 \mathrm{~mol} \mathrm{dm}^{-3}\right)$ we may assume for this drug (Miyajima et al., 1983; Ribeiro et al., 2009) that

$\ln \gamma=b c$

where $b\left(\mathrm{dm}^{3} \mathrm{~mol}^{-1}\right)$ is a constant (whose value can be determined from Eqs. 4 and 5). Combining Nernst-Hartley's equation (Eq. (5)) and Eq. (7) we obtain the values for the activity coefficients of L-Dopa (Table 4). We can observe, for both temperatures, that they decrease significantly with the increase of the concentration $(<6 \%)$ and, concerning the effect of temperature, there are no appreciable differences among them $(<0.2 \%)$. Despite of the limitations of this estimative method, we may interpret that variation on the basis of the increasing of the solute-solvent interactions with the increasing of the concentration (more favoured with respect to the solute-solute ones) reflecting all contributions from water molecules, including those beyond the first layer which would not be firmly enough to move as a unit with the ion.

From the extended Stokes-Einstein equation (Eq. (8)) (ErdeyGruz, 1974), which consider the solvent as a continuum characterized by its bulk viscosity value, it is also possible to estimate the hydrodynamic radius, $R_{h}$, of L-Dopa in these solutions,

$D=\frac{k_{B} T}{6 \pi \eta R_{h}}$

Table 4

Activity coefficients, $\gamma$, for L-Dopa aqueous solutions, evaluated from Eq. (5).

\begin{tabular}{lll}
\hline$c\left(\mathrm{~mol} \mathrm{dm}^{-3}\right)$ & $\gamma$ & \\
\cline { 2 - 3 } & $T(\mathrm{~K})=298.15$ & $T(\mathrm{~K})=310.15$ \\
\hline 0.000250 & 0.996 & 0.996 \\
0.000500 & 0.992 & 0.992 \\
0.001001 & 0.985 & 0.984 \\
0.001751 & 0.974 & 0.972 \\
0.002501 & 0.963 & 0.961 \\
0.003749 & 0.944 & 0.942 \\
\hline
\end{tabular}

$\mathrm{u}(c)=5 \times 10^{-6} \mathrm{~mol} \mathrm{dm}^{-3}$.
Table 5

Hydrodynamic radius, $R_{h}$, of L-Dopa in aqueous solutions at two temperatures, $T$.

\begin{tabular}{llllll}
\hline \multirow{2}{*}{$c\left(\mathrm{~mol} \mathrm{dm}^{-3}\right)$} & \multicolumn{2}{l}{$D \eta / T\left(10^{-15} \mathrm{~m} \mathrm{~s}^{-1} \mathrm{~kg} \mathrm{~K}^{-1}\right)$} & & \multicolumn{2}{l}{$R_{h}\left(10^{-9} \mathrm{~m}\right)$} \\
\cline { 2 - 3 } \cline { 5 - 6 } & $T(\mathrm{~K})=298.15$ & $T(\mathrm{~K})=310.15$ & & $T(\mathrm{~K})=298.15$ & $T(\mathrm{~K})=310.15$ \\
\hline 0 & 1.902 & 1.897 & 0.385 & 0.386 \\
0.000250 & 1.903 & 1.897 & 0.386 & 0.387 \\
0.000500 & 1.904 & 1.897 & & 0.389 & 0.389 \\
0.001001 & 1.904 & 1.898 & 0.393 & 0.393 \\
0.001751 & 1.905 & 1.899 & 0.394 & 0.392 \\
0.002501 & 1.906 & 1.900 & 0.400 & 0.393 \\
0.003749 & 1.907 & 1.902 & 0.396 & 0.392 \\
0.005001 & 1.908 & 1.904 & 0.390 & 0.384 \\
0.006000 & 1.909 & 1.905 & 0.381 & 0.382 \\
0.007001 & 1.910 & 1.907 & 0.369 & 0.368 \\
\hline
\end{tabular}

$\mathrm{u}(c)=5 \times 10^{-6} \mathrm{~mol} \mathrm{dm}^{-3}$.

where $k_{B}$ and $\eta$ are Boltzmann's constant and the viscosity of the solvent at temperature $T$. Although this relation is only approximated (arising from the acceptance that the structure of both the solute kinetic species and the solvent are not considered together with the assumption of this viscosity is the only responsible of the diffusivity reduction), it can be used to estimate the radius of the moving species, since L-Dopa molecules are large enough when compared with the water molecules. Table 5 gives the $(D \eta / T)$ values whose variation observed is relatively small (less than $0.5 \%$ at both temperatures) and within the imprecision of the diffusion measurements. The values calculated for the effective hydrodynamic radius $R_{h}$ of L-Dopa in these solutions are also collected in Table 5. As it can be observed, the maximum variation observed in these $R_{h}$ values, with respect to the limiting one at infinitesimal concentration, is around $4 \%$.

From the $R_{h}$ value at infinitesimal concentration thus determined, it is straightforward to obtain the limiting hydrodynamic molar volume of the L-Dopa, $\bar{V}^{0}$. These values, calculated from the approximation of spherical shape for the L-Dopa molecules, are: $144 \mathrm{~cm}^{3}$ and $145 \mathrm{~cm}^{3}$, at 298.15 and $310.15 \mathrm{~K}$, respectively.

Table 6 shows the experimental density values of L-Dopa for both the concentration range and temperatures studied. These data were linearly fitted by using a least-squares regression method to analyse their dependence with concentration. The values obtained are summarized in Table 7. From them it can be seen that both lines are almost mutually parallels which implies that temperature has no further influence on the behaviour of this physicochemical property with concentration.

Apparent molar volumes, $\phi_{\mathrm{V}}$, for these L-Dopa aqueous solutions are also collected in Table 6 . They were calculated by using the equation:

$\phi_{V}=\frac{V-V_{\mathrm{H}_{2} \mathrm{O}}}{m}=\frac{M}{\rho}+\frac{1000}{m}\left(\frac{1}{\rho}-\frac{1}{\rho_{\mathrm{H}_{2} \mathrm{O}}}\right)$

where $M\left(=197.17 \mathrm{~g} \mathrm{~mol}^{-1}\right)$ is the molar mass of the solute, $V$ is the volume of a solution of molality $m$ and $V_{\mathrm{H}_{2} \mathrm{O}}$ and $\rho_{\mathrm{H}_{2} \mathrm{O}}$ are the volume and density of pure water, respectively. They show a good agreement with data previously published (Table II in Marriott et al., 1998).

The value at infinitesimal concentration was determined by using the Masson equation (Masson, 1929), which is applicable for dilute aqueous solutions of electrolytes:

$\phi_{V}=\phi_{V}^{0}+S_{V}^{0} \sqrt{c}$

where $\phi_{V}^{0}$ is the apparent partial molar volume at infinitesimal concentration (at this limiting condition $\phi_{V}^{0}=\bar{V}_{2}^{0}$, i.e., the apparent molar volume of the solute equals its partial molar volume) and $S_{V}^{0}$ is the experimental slope which value depends on both the nature of the solute and the temperature and has been correlated to the 
Table 6

Experimental density data, $\rho$, and apparent molar volumes for aqueous L-Dopa solutions at various concentrations, $m$, and temperatures, $T$.

\begin{tabular}{|c|c|c|c|c|c|c|}
\hline \multirow[t]{2}{*}{$m\left(\mathrm{~mol} \mathrm{~kg}^{-1}\right)$} & \multicolumn{3}{|c|}{$T(\mathrm{~K})=298.15$} & \multicolumn{3}{|c|}{$T(\mathrm{~K})=310.15$} \\
\hline & $\rho\left(\mathrm{g} \mathrm{cm}^{-3}\right)$ & $10^{6} \Delta^{(\mathrm{a})}$ & $\phi_{\mathrm{V}}\left(\mathrm{cm}^{3} \mathrm{~mol}^{-1}\right)$ & $\rho\left(\mathrm{g} \mathrm{cm}^{-3}\right)$ & $10^{6} \Delta^{(\mathrm{a})}$ & $\phi_{\mathrm{V}}\left(\mathrm{cm}^{3} \mathrm{~mol}^{-1}\right)$ \\
\hline $0.000261_{7}$ & 0.997069 & 0.5 & $117.0_{4}$ & 0.993357 & 0.8 & $106.3_{3}$ \\
\hline $0.000486_{0}$ & 0.997084 & 1.1 & $123.6_{6}$ & 0.993363 & 2.4 & $113.0_{0}$ \\
\hline 0.001009 & 0.997125 & 0.8 & $120.8_{2}$ & 0.993408 & 0.4 & 122.99 \\
\hline 0.001757 & 0.997175 & 0.8 & $124.9_{3}$ & 0.993457 & 1.3 & $126.7_{4}$ \\
\hline 0.002504 & 0.997230 & 7.0 & $124.6_{5}$ & 0.993513 & 0.7 & $125.6_{5}$ \\
\hline 0.004972 & 0.997399 & 0.8 & $126.6_{7}$ & 0.993681 & 0.7 & $127.5_{3}$ \\
\hline 0.006990 & 0.997545 & 0.7 & $126.1_{9}$ & 0.993826 & 1.1 & $127.0_{3}$ \\
\hline 0.007476 & 0.997588 & 1.1 & $125.0_{2}$ & 0.993891 & 1.3 & $122.8_{3}$ \\
\hline
\end{tabular}

(a) $\Delta$ stands for standard deviation of all the measurements; $\mathrm{u}(m)=2 \times 10^{-6} \mathrm{~mol} \mathrm{~kg}^{-1} ; \mathrm{u}(\rho)=5 \times 10^{-6} \mathrm{~g} \mathrm{~cm}^{-3} ; \mathrm{u}(T)=0.005 \mathrm{~K}$.

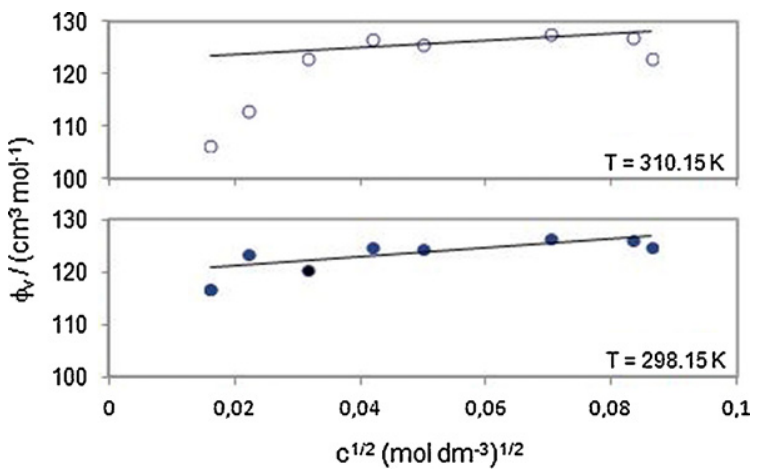

Fig. 2. Plot of $\phi_{v}$ values against $c^{1 / 2}$ at different temperatures (the tendency straight lines are drawn).

Table 7

Values of $\rho^{0}$ and $b$ for the concentration dependence of $D$ in aqueous solutions of L-Dopa at $298.15 \mathrm{~K}$ and $310.15 \mathrm{~K}^{\mathrm{a}}$.

\begin{tabular}{llcl}
\hline$T(\mathrm{~K})$ & $\rho^{0}\left(\mathrm{~g} \mathrm{~cm}^{-3}\right)^{\mathrm{b}}$ & $b^{\prime}\left(\mathrm{dm}^{3} \mathrm{~mol}^{-1}\right)$ & $r^{2}$ \\
\hline 298.15 & $0.997050 \pm 0.000002$ & $0.0711 \pm 0.0005$ & 0.999 \\
310.15 & $0.993335 \pm 0.000006$ & $0.072 \pm 0.001$ & 0.998 \\
\hline
\end{tabular}

a These linear fittings were performed from the Table 6 data, $b^{\prime}$ being the slope of the fitting.

b In very good agreement with literature data (Lide, 2007-2008).

solute-solute interactions taking place in solution. These limiting values are $121.6( \pm 1.5) \mathrm{cm}^{3} \mathrm{~mol}^{-1}$ and $122.4( \pm 1.9) \mathrm{cm}^{3} \mathrm{~mol}^{-1}$ for 298.15 and $310.15 \mathrm{~K}$, respectively. They were found by disregarding the experimental points at low concentrations (Fig. 2). These limiting values agree well with that of $126.35 \mathrm{~cm}^{3} \mathrm{~mol}^{-1}$, independent of the temperature, previously reported in the literature (Marriott et al., 1998) by considering a linear dependence between the apparent partial molar volume and the molal concentration.

\section{Table 8}

Experimental viscosity data, $\eta$, for L-Dopa aqueous solutions at various concentrations. $m$. and temperatures, $T$.

\begin{tabular}{lllll}
\hline$m\left(\mathrm{~mol} \mathrm{~kg}^{-1}\right)$ & \multicolumn{3}{l}{$\eta(\mathrm{mPa})$} & \\
\cline { 2 - 5 } & $T(\mathrm{~K})=298.15$ & $10^{4} \Delta^{\mathrm{a}}$ & $T(\mathrm{~K})=310.15$ & $10^{4} \Delta^{\mathrm{a}}$ \\
\hline $0.000261_{7}$ & 0.8907 & 1.5 & 0.6924 & 1.3 \\
$0.000486_{0}$ & 0.8908 & 1.5 & 0.6925 & 2.7 \\
0.001009 & 0.8910 & 0.1 & 0.6928 & 1.6 \\
0.001757 & 0.8913 & 0.8 & 0.6932 & 0.9 \\
0.002504 & 0.8917 & 2.8 & 0.6936 & 3.6 \\
0.004972 & 0.8928 & 1.6 & 0.6949 & 2.7 \\
0.006990 & 0.8937 & 0.9 & 0.6960 & 1.1 \\
0.007476 & 0.8939 & 0.6 & 0.6963 & 1.0
\end{tabular}

a $\Delta$ stands for the standard deviation of all the measurements; $\mathrm{u}(m)=2 \times 10^{-6} \mathrm{~mol} \mathrm{~kg}^{-1} ; \mathrm{u}(\eta)=1 \times 10^{-3} \mathrm{mPas} ; \mathrm{u}(T)=0.02 \mathrm{~K}$.
Table 9

Coefficient values obtained from the analysis of the viscosity-concentration dependence for L-Dopa aqueous solutions by using the Jones-Dole equation.

\begin{tabular}{llll}
\hline$T(\mathrm{~K})$ & $A\left(\mathrm{dm}^{3 / 2} \mathrm{~mol}^{-1 / 2}\right)$ & $B\left(\mathrm{dm}^{3} \mathrm{~mol}^{-1}\right)$ & $r^{2}$ \\
\hline 298.15 & $-0.002 \pm 0.002$ & $0.52 \pm 0.02$ & 0.999 \\
310.15 & $-0.001 \pm 0.002$ & $0.80 \pm 0.02$ & 0.999 \\
\hline
\end{tabular}

In Table 8 the experimental viscosity values of L-Dopa, obtained for the concentration range and the temperatures studied, are collected. As it can be ascertained, an important decreasing of these values was obtained when the temperature increases, being the influence of the concentration very small and in the opposite sense. Moreover, the increasing of the viscosity values with the concentration of the solution is bigger for the highest temperature studied $\left(0.55 \mathrm{mPa} \mathrm{s} \mathrm{kg} \mathrm{mol}^{-1}\right.$ at $310.15 \mathrm{~K}_{\text {against }} 0.43 \mathrm{mPa} \mathrm{s} \mathrm{kg} \mathrm{mol}{ }^{-1}$ at $298.15 \mathrm{~K})$.

The analysis of the concentration influence on the viscosity of the solution was performed from the well-known Jones-Dole equation, valid for solutions of electrolytes, (although L-Dopa is not an electrolyte it has a zwitterion structure)

$\frac{\eta}{\eta_{0}}=1+A c^{1 / 2}+B c+D c^{2}$

where $\eta_{0}$ and $\eta$ are the viscosities of the pure solvent and the solution, respectively, and the $A$ and $B$ coefficients are depending on both the solute and the solvent, as well as on the temperature and pressure (Table 9). This $B$-coefficient reflects the effect of the solute-solvent interactions occurring in the solution and it is used as a criterion of measuring the structure-making and structure-breaking capacity of the solute on the solution structure. The $A$-coefficient has been related to the solute-solute interactions taking place in the solution. The $D$-coefficient depends on both the solute-solute and solute-solvent interactions and it becomes important only at high solute concentration $\left(>0.5 \mathrm{~mol} \mathrm{dm}^{-3}\right)$ (Donald et al., 1995) and, therefore, it was disregarded for this analysis in Eq. (11).

The large and positive values of the $B$-coefficient strengthened by the temperature increasing $(d B / d T=0.02)$ suggest that this drug has structure-making capacity which means that L-Dopa possesses the ability to increase water structure in the solution. This fact is in agreement with that derived from the analysis of the activity coefficients (see Table 4).

\section{Conclusions}

It was possible to determine experimental mutual diffusion coefficients, densities and viscosities of binary aqueous solutions of L-Dopa at $298.15 \mathrm{~K}$ and $310.15 \mathrm{~K}$. Regarding the results obtained for the diffusion coefficient, possible electrostatic interactions can be present, resulting in a decrease in the diffusion coefficient values. From these data it is still possible to conclude that the increase in 
the temperature contributes to an increase in the average velocity of the ions and, consequently, to a raise of the diffusion coefficient.

Both the density and the viscosity of these solutions show a linear dependence with the concentration. From the viscosity $A$ and $B$-coefficient values found it can be concluded that solute-solvent interactions are predominant and became more important when the temperature increases.

These results became more significant when the pharmaceutical applications of this drug and its behaviour at physiological temperature are having in mind. This fact provides the usefulness of the transport data to model the diffusion for in vivo applications.

\section{Acknowledgments}

Financial support from FCT (FEDER)-PTDC/AAC-CLI/098308/ 2008 and PTDC/AAC-CLI/118092/2010 is gratefully acknowledged. MCFB is grateful for the SFRH/BD/72305/2010 grant.

\section{References}

Callendar, R., Leaist, D.G., 2006. Diffusion coefficients for binary, ternary and polydisperse solutions from peak-width analysis of Taylor dispersion profiles. J. Solut. Chem. 35, 353-379.

Carlsson, A., 2002. Treatment of Parkinson's with L-Dopa. The early discovery phase and a comment on current problems. J. Neural Transm. 109, 777-787.

Chen, X., Xie, J., Li, C., Hu, Z., Chen, X., 2004. Investigation of the factors that induce analyte peak splitting in capillary electrophoresis. J. Sep. Sci. 27, 10051010.

Cotzias, G.C., Van Woert, M.H., Schiffer, L.M., 1967. Aromatic amino acids and modification of parkinsonism. N. Eng. J. Med. 276, 374-379.

Cotzias, G.C., Papavasiliou, P.S., Gellene, R., 1969. Modification of parkinsonism: chronic treatment with L-Dopa. N. Eng. J. Med. 280, 337-345.

Donald, H., Jenkins, B., Marcus, Y., 1995. Viscosity B-coefficients of ions in solution. Chem. Rev. 95, 2695-2724.

Erdey-Gruz, T., 1974. Transport phenomena in aqueous solutions, 2nd ed. Adam Hilger, London, p. 151.
Kestin, J., Sokolov, M., Wakerham, W.A., 1978. Viscosity of liquid water in the range $-8^{\circ} \mathrm{C}$ to $150^{\circ} \mathrm{C}$. J. Phys. Chem. Ref. Data 7, 941-948.

Lide, D.R. (Ed.), 2007-2008. Handbook of Chemistry and Physics. , 88th ed. CRC Press, Boca Raton, USA, p. 6-6.

Marriott, R.A., Hakin, A.W., Liu, J.L., 1998. Modeling of thermodynamic properties of amino acids and peptides using additivity and HKF theory. J. Solut. Chem. 27, 771-802.

Masson, D.O., 1929. Solute molecular volumes in relation to solvation and ionization. Phil. Mag. 8, 218-235.

Miyajima, K., Sawada, M., Nakagaki, M., 1983. Viscosity B-coefficients, apparent molar volumes, and activity coefficients for alpha-cyclodextrin in aqueous solutions. Bull. Chem. Soc. Jpn. 56, 3556-3560.

Ribeiro, A.C.F., Lobo, V.M.M., Leaist, D.G., Natividade, J.J.S., Verissimo, L.P., Barros, M.C.F., Cabral, A.M.T.D.P.V., 2005. Binary diffusion coefficients for aqueous solutions of lactic acid. J. Solut. Chem 34, 1009-1016.

Ribeiro, A.C.F., Santos, A.C.G., Lobo, V.M.M., Veiga, F.J.B., Cabral, A.M.T.D.P.V., Esteso, M.A., Ortona, O., 2009. Binary mutual diffusion coefficients of isoniazid aqueous solutions at (298.15 and 310.15) K. J. Chem. Eng. Data 54, 3235-3237.

Ribeiro, A.C.F., Barros, M.C.F., Lobo, V.M.M., Quintanilla, G., Esteso, M.A., 2010. Diffusion coefficients of the ternary system calcium chloride-caffeine-water at (25 and 37) ${ }^{\circ} \mathrm{C}$. J. Chem. Eng. Data 55, 897-900.

Ribeiro, A.C.F., Barros, M.C.F., Lobo, V.M.M., Sobral, A.J.F.N., Fangaia, S.I.G., Nicolau, P.M.G., Guerra, F.A.D.R.A., Esteso, M.A., 2011a. Interaction between calcium chloride and some carbohydrates as seen by mutual diffusion at $25^{\circ} \mathrm{C}$ and $37^{\circ} \mathrm{C}$. Food Chem. 124, 842-849.

Ribeiro, A.C.F., Gomes, J.C.S., Barros, M.C.F., Lobo, V.M.M., Esteso, M.A., 2011b. Diffusion coefficients of nickel chloride in aqueous solutions of lactose at $T=298.15 \mathrm{~K}$ and $T=310.15 \mathrm{~K}$. J. Chem. Therm. 43, 270-274.

Ribeiro, A.C.F., Sobral, A.J.F.N., Simoes, S.M.N., Barros, M.C.F., Lobo, V.M.M., Cabral, A.M.T.D.P.V., Veiga, F.J.B., Santos, C.I.A.V., Esteso, M.A., 2011c. Transport properties of aqueous solutions of sodium alginate at $29815 \mathrm{~K}$. Food Chem. 125, 1213-1218.

Ribeiro, A.C.F., Barros, M.C.F., Verissimo, L.M.P., Santos, C.I.A.V., Cabral, A.M.T.D.P.V., Gaspar, G.D., Esteso, M.A., 2012. Diffusion coefficients of paracetamol in aqueous solutions. J. Chem. Therm. 54, 97-99.

Taylor, G., 1953. Dispersion of soluble matter in solvent flowing slowly through a Tube. Proc. R. Soc. London A 219, 186-203.

Tyrrell, H.J.V., Harris, K.R., 1984. Diffusion in Liquids, 2nd ed. Butterworths, London, pp. 298, 403.

Valente, A.J.M., Ribeiro, A.C.F., Rita, M.B.B.J., Carvalho, R.A., Esteso, M.A., Lobo, V.M.M., 2011. Transport properties of aqueous solutions of calcium lactate in the absence and presence of beta-cyclodextrin. J. Mol. Liq. 161, 125-131. 